J. Clin. Chem. Clin. Biochem.

Vol. 20, 1982, pp. $457-460$

\title{
Comparison of Two Methods for Very Low Density and Low Density Lipoprotein Cholesterol Determination
}

\author{
By G. E. Hoffmann
}

\section{Institute of Clinical Chemistry, Harlaching City Hospital, München}

\section{E. Schleicher}

Institute of Clinical Chemistry, Schwabing City Hospital, München

\section{Weiss and Susanne Hoffmann}

Institute of Clinical Chemistry, Harlaching City Hospital, München

(Received October 30, 1981)

Summary: It is shown that VLDL-cholesterol cannot be calculated from serum triacylglycerol at elevated triacylglycerol concentrations (above $2 \mathrm{~g} / 1)$. Using the method of Friedewald et al. ((1972) Clin. Chem. 18, 499-502), VLDL-cholesterol is usually overestimated in these sera and, consequently, LDL-cholesterol underestimated. Quantitative lipoprotein electrophoresis according to Wieland \& Seidel ((1978) Innere Medizin 5, 290-300), on the other hand, yields VLDL-cholesterol values which correspond to ultracentrifugation data within narrow limits, even in sera with high triacylglycerol contents. A nomogram has been developed for the evaluation of electropherogram.

\section{Vergleich zweier Methoden zur Bestimmung von VLDL- und LDL-Cholesterin}

Zusammenfassung: Es konnte gezeigt werden, dạß unter Vèrwendung der von Friedewald et al. ((1972) Clin. Chem. 18, 499-502) angegebenen Formel der VLDL-Cholesteringehalt aus den Triacylglycerinkonzentrationen, sofern diese $2 \mathrm{~g} / 1$ übersteigen, nicht bestimmit werden kann. Der VLDL-Cholesteringehalt wird zu hoch und somit der LDL-Cholesteringehalt zu niedrig kalkuliert. Mit der von Wieland \& Seidel ((1978) Innere Medizin 5, 290-300) beschriebenen quantitativen Lipoproteinelektrophorese findet man Werte für VLDL-Cholesterin, die auch bei erhöhten Triacylglycerinkonzentrationen (über $2 \mathrm{~g} / 1$ ) gut mit den Ergẹnissen von Ultrazentrifugationsstudien übereinstimmen. Für die Auswertung der Ėlektropherogramme wurde ein Nomogramm èntwickèlt.

\section{Introduction}

Simple precipitation methods are now available for the determination of HDL-cholesterol while the direct measurement of VLDL- and LDL̈-cholesterol requires more laborious techniques. Usually, the VLDLcholesterol concentration is derived indirectly from the serum triacylglycerol content by a formula described by Friedewald et al. (1). LDL-cholesterol is then calculated by subtracting HDL- and VLDL-cholesterol from total serum cholesterol.

In this paper, the calculation method is compared with a more recently developed electrophoretic technique (2). Ultracentrifugation is used as a reference method.

In contrast to the international convention (SI System) and the rules of this journal, the term "percent" is used in the calculation procedure for $\alpha$ - and $\beta$-lipoprotein cholesterol fractions in the lipoprotein electrophoresis. This takes into account that all commercially available densitometers print out densitometric results as percentages. Thus the data can be applied without further transformation.

\section{Materials and Methods}

Lipoproteins were analyzed in fasting sera of hospitalized patients by 2 commercially available methods $(2,3)$. Reagents for method A, i.e. polyanion precipitation with phosphotungstate and magnesium chloride were obtained from Boehringer, Mannheim, Germany, and test combinations for method $B$, i.e. lipoprotein clectrophoresis (Lipidophor all-in) from Immuno Diagnostics, Heidelberg, Germany. Electropherograms were monitored on the densitometer Elscript III from Hirschmann, Munich, Germany. Serum cholesterol and tri- 
acylglycerol were measured enzymatically $(4,5)$ using test combinations from Boehringer, Mannheim.

In some selected samples VLDL were separated from other lipoproteins by flotation in the preparative ultracentrifuge (Beckman, Spinco Model L5-65) using a SW 65 rotor for $18 \mathrm{~h}$ at $105000 \mathrm{~g}$. The top fraction was washed in isotonic $\mathrm{NaCl}$ solution and recentrifuged under the same conditions and cholesterol determined (VLDL-cholesterol).

\section{Calculations}

LDL-cholesterol (LDLC) concentrations were calculated according to Friedewald et al. (1):

LDLC $=$ cholesterol - HDLC - triacylglycerol $/ 5$.

All concentrations are expressed as $\mathrm{g} / \mathrm{l}$. The figure "triacylglycerol/5" stands for VLDL-cholesterol.

$\alpha-$, pre- $\beta$-, and $\beta$-lipoprotein cholesterol concentrations which, in general, correspond to HDL-, VLDL- and LDL-cholesterol concentrations were calculated according to Wieland \& Seidel (2). In their procedure the $\alpha-$, pre- $\beta$, and $\beta$-lipoprotein fractions are quantified by the "relative optical densities" of the 3 bands expressed as "percentages of the total density" of the electropherogram. The cholesterol content of the 3 different lipoprotein fractions is then calculated from the "relative optical densities", from total cholesterol and from distinct factors derived empirically from ultracentrifugation studies $(2,7)$.
Because the original equations are relatively intricate for the routine use, a nomogram ${ }^{1}$ ) was developed on the basis of the following modified equations, where pre- $\beta(\%)$ is replaced by

$$
\text { pre- } \beta(\%)=100-\alpha(\%)-\beta(\%) \text { : }
$$

$\alpha$-lipoprotein cholesterol

if cholesterol

$$
=\frac{\alpha(\%)}{161-0.610 \alpha(\%)+1.136 \beta(\%)}=\mathrm{A}
$$

$$
\begin{aligned}
& \frac{\beta \text {-lipoprotein cholesterol }}{\text { cholesterol }}= \\
& =\frac{\beta(\%)}{58.6-0.222 \alpha(\%)+0.414 \beta(\%)}=\mathrm{B}
\end{aligned}
$$

The 4 variables $A, B, \alpha(\%)$, and $\beta(\%)$ can be expressed as linear axes of a nomogram. $\alpha$ - or $\beta$-lipoprotein cholesterol concentrations are then obtained by multiplication of $\mathrm{A}$ or $\mathrm{B}$ with total serum cholesterol (fig. 1).

1) available from Immuno Diagnostica, Heidelberg, Germany
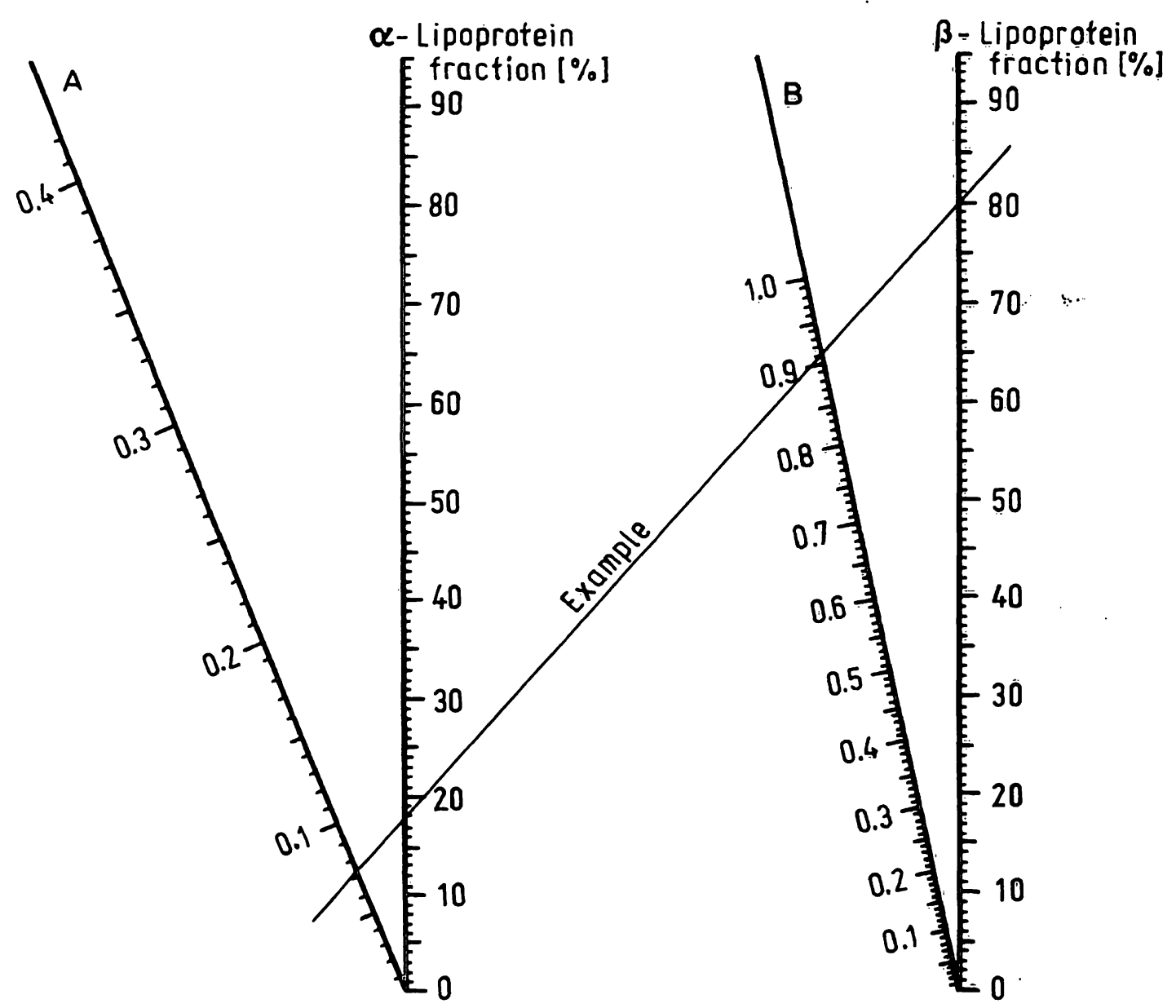

Fig. 1. Nomogram for the evaluation of lipoprotein electrophoreses.

Example: cholesterol $=2.6 \mathrm{~g} / \mathrm{l}$, fraction of $\alpha$-lipoproteins $=18 \%$, of $\beta$-lipoproteins $=80 \% . \quad \mathrm{A}=0.073 \quad \mathrm{~B}=.0 .91$. $\alpha$-lipoprotein cholesterol $=\mathrm{A} \times$ cholesterol $=0.19 \mathrm{~g} / 1 \quad \beta$-lipoprotein cholesterol $=\mathrm{B} \times$ cholesterol $=2.37 \mathrm{~g} / 1$. 


\section{Results}

Despite a high standard deviation from regression (S.D. $=0.09 \mathrm{~g} / 1$ ) there is a significant correlation $(r=0.781)$ between electrophoretically determined pre- $\beta$-lipoprotein cholesterol and total triacylglycerol or VLDL-cholesterol according to Friedewald et al. (1), respectively (fig. 2). The figure shows clearly that "triacylglycerol/5" which has been suggested by Friedewald et al. (1) for the calculation of VLDL-cholesterol concentrations cannot be confirmed from our data.

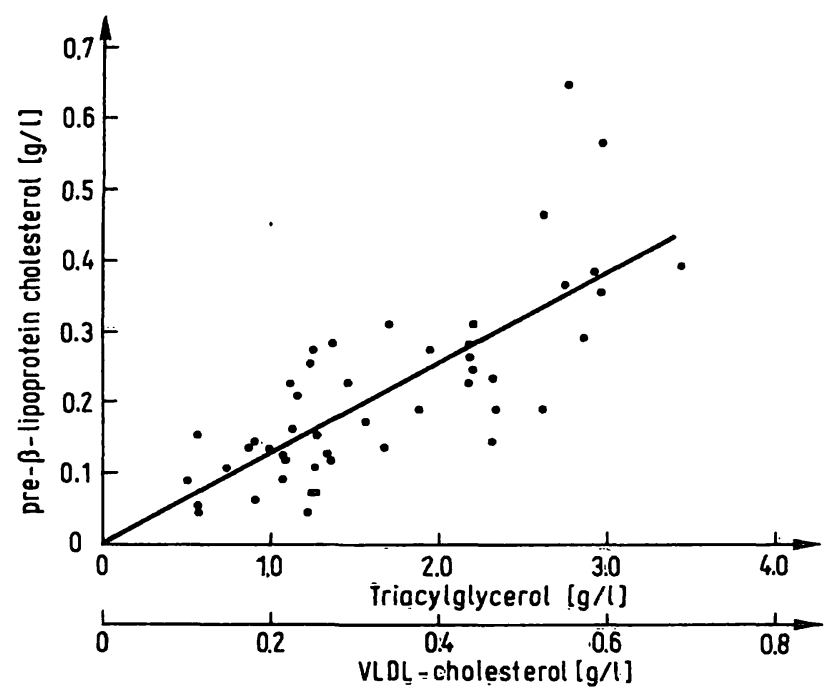

Fig. 2. Correlation between pre- $\beta$-lipopopotein cholesterol and total triacylglycerol in 51 sera. The $2^{\text {nd }}$ abscissa indicates calculated VLDL-cholesterol values ("triacylglycerol/5").

A figure of "triacylglycerol/8", as derived from the equation of regression ( $\mathrm{tab}$. 1) would fit better. It must, however, be recognized that individual values vary within the wide limits of "triacylglycérol/4" to "triacylglycerol/ 24 ". At low triacylglycerol concentrations (below 2.0 $\mathrm{g} / \mathrm{l})$ the absolute differences between pre- $\dot{\beta}$-lipoprotein cholesterol and "triacylglycerol/8" do not exceed $0.15 \mathrm{~g} / 1$ and should be neglected considering the analytical errör. At higher concentrations differences of even more than $0.3 \mathrm{~g} / 1$ occur.

Tab. 1. Equations of regression from figures 2 and $3(n=51$ in each case).

\begin{tabular}{|c|c|c|c|c|}
\hline$\cdot \mathbf{y}$ & $\mathbf{x}$ & $\begin{array}{l}\text { Equation } \\
\text { of regression }\end{array}$ & $\begin{array}{l}\text { Corre- } \\
\text { lation } \\
\text { coeffi- } \\
\text { cient }\end{array}$ & $\begin{array}{l}\text { S.D. } \\
\text { from re- } \\
\text { gression }\end{array}$ \\
\hline $\begin{array}{l}\text { pre- } \beta \text {-lipo- } \\
\text { protein } \\
\text { cholesterol }\end{array}$ & $\begin{array}{l}\text { Triacyl- } \\
\text { glycerol }\end{array}$ & $y=0.128 x+0.0$ & 0.781 & 0.086 \\
\hline $\begin{array}{l}\text { HDL- } \\
\text { cholesterol }\end{array}$ & $\begin{array}{l}\alpha \text {-lipo- } \\
\text { protein } \\
\text { cholesterol' }\end{array}$ & $y=0.560 x+0.18$ & 0.815 & 0.087 \\
\hline $\begin{array}{l}\text { LDL- } \\
\text { cholesterol }\end{array}$ & $\begin{array}{l}\beta \text {-lipo- } \\
\text { protein } \\
\text { cholesterol }\end{array}$ & $y=1.090 x+0.24$ & 0.923 & 0.159 \\
\hline
\end{tabular}

As a consequence of the frequent overestimation of VLDL-cholesterol, the Friedewald formula tends to yield too low LDL-cholesterol values (fig. 3). Setting the limit of decision at $1.9 \mathrm{~g} / 1$ LDL-cholesterol (6), only 23 out of 51 examined patients are classified as high-risk by this method as compared to 30 patients, when the electrophoretic method is applied. All 51 patients had total cholesterol levels between 2.0 and $3.0 \mathrm{~g} / 1$, and triacylglycerol levels between 0.5 and $3.5 \mathrm{~g} / 1$.

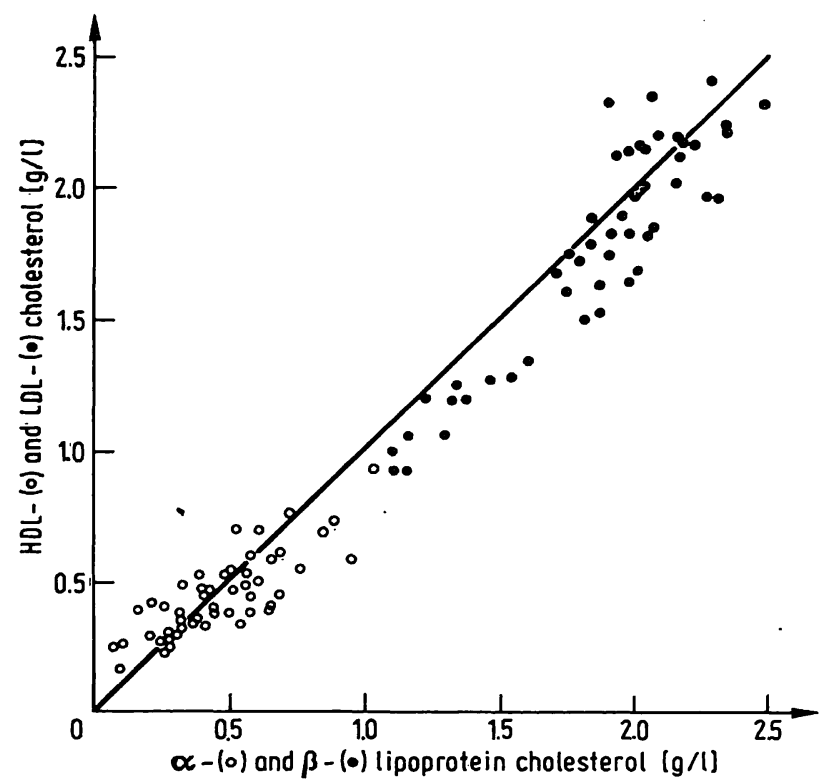

Fig. 3. Comparison of the Friedewald method (ordinate) and the Wieland \& Seidel method (abscissa).

$-=$ line of equality $(y=x)$

In order to decide which method is more reliable, we studied an additional group of 8 patients with triacylglycerol values between 2.0 and $3.6 \mathrm{~g} / \mathrm{l}$, using methods $A$ and $B$, and ultracentrifugation as a reference method. From figure 4 it is evident that VLDL-cholesterol in

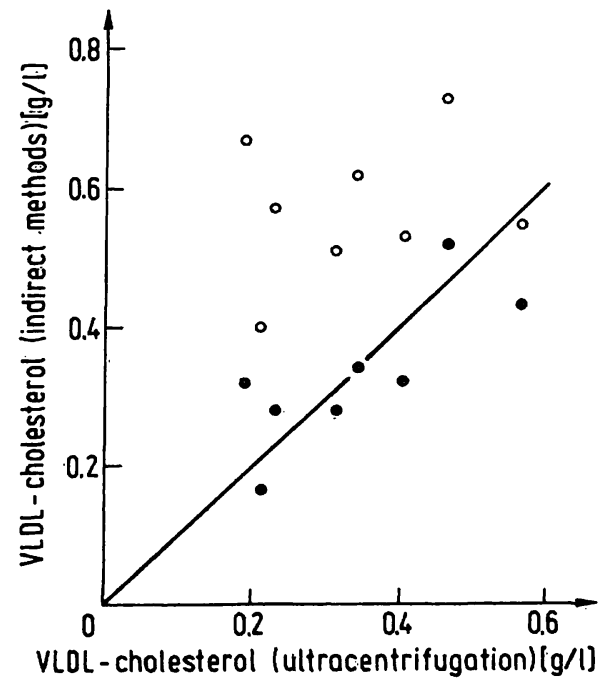

Fig. 4. VLDL-cholesterol concentrations determined after ultracentrifugation as compared to the corresponding values from the indirect methods $\mathrm{A}$ (open circles $=$ Friedewald method) and B (filled circles = Wieland \& Seidel method). $-=$ line of equality $(y=x)$ 
most cases is overestimated by the Friedewald method while electrophoretic data correspond to the reference method within the limits of $\pm 0.15 \mathrm{~g} / \mathrm{l}$. Figure 3 further demonstrates that $\alpha$-lipoprotein cholesterol values from electrophoresis and HDL-cholesterol values obtained by precipitation agree within the limits of $\pm 0.2 \mathrm{~g} / 1$. The line of regression, however, deviates markedly from the line of equality (tab. 1), indicating some systematic difference between the two methods.

\section{Discussion}

The Friedewald formula is based on the assumptions that the greatest part of serum triacylglycerol is present in the VLDL fraction and that the ratio of triacylglycerol to VLDL-cholesterol is constant. This may hold under normal but not under all pathological conditions. It has been demonstrated in this paper (fig. 3,4 ) that the calculation of VLDL-cholesterol from triacylglycerol according to Friedewald et al. (1) leads frequently to overestimation of VLDL-cholesterol and, consequently, to underestimation of LDL-cholesterol. In contrast, the electrophoretic method described by Wieland \& Seidel (2) yields pre- $\beta$-lipoprotein cholesterol values which correspond to ultracentrifugation data within the limits of $\pm 0.15 \mathrm{~g} / 1$. At normal or slightly elevated triacyl-

\section{References}

1. Friedewald, W. T., Levy, R. I. \& Frederickson, D. S. (1972) Clin. Chem. 18, 499-502.

2. Wieland, H. \& Seidel, D. (1978) Innere Medizin 5, 290-300.

3. Warnick, G. R., Cheung, M. C. \& Albers, J. J. (1979) Clin. Chem. 25, 596-604.

4. Röschlau, P., Bernt, E. \& Gruber, W. (1974) Z. Klin. Chem. Klin. Biochem. 12, 403-407. glycerol concentrations (up to $2.0 \mathrm{~g} / 1$ ), the electrophoretically determined pre- $\beta$-lipoprotein cholesterol was found to be equivalent to the figure "triacylglycerol/ 8 " within the same limits of $\pm 0.15 \mathrm{~g} / 1$.

Above this limit ( $2.0 \mathrm{~g} / 1)$, VLDL-cholesterol cannot be estimated from triacylglycerol. This is in contrast to Friedewald et al. (1), who give a limit of $4.0 \mathrm{~g} / 1$ triacylglycerol. The quantitative lipoprotein electrophoresis, on the other hand, is a suitable routine method for the distinct measurement of VLDL-cholesterol and LDLcholesterol in sera with elevated (more than $2.0 \mathrm{~g} / \mathrm{l}$ ) triacylglycerol.

Regarding the determination of HDL-cholesterol, we observed small but șystematic differences between the 2 methods compared (fig. 3). . Warnick et al. (3) observed that the phosphotungstate method yields somewhat too low results in the upper concentration range (aboye $0.6 \mathrm{~g} / 1$ ). Seidel (7), on the other hand, reported that electrophoretically determined $\alpha$-lipoprotein cholesterol differed up to $0.2 \mathrm{~g} / 1$ from HDL-cholesterol values obtained by ultracentrifugation. This may be due to the fact, that $\alpha$-lipoprotein and HDL are not exactly identical and that the HDL-fraction is not homogenous. Because $\mathrm{HDL}_{2}$ and $\mathrm{HDL}_{3}$ differ markedly with respect to their cholesterol content (6), the constant factor given by Wieland \& Seidel (2) for the calculation of total $\alpha$-lipoprotein cholesterol may be erroneous in cases of abnormal $\mathrm{HDL}_{2} / \mathrm{HDL}_{3}$-ratios.

5. Wahlefeld, A. (1974) in Methoden der enzymatischen Analyse (Bergmeyer, H. U. ed.) pp. 1878-1882. Verlag Chemie, Weinheim.

6. Assmann, G. \& Schriewer, H. (1980) High Density Lipoproteine: Analytik, Biochemie und Klinik. Münchner Med. Wochenschr. Suppl.

7. Seidel, D. (1979) HDL Methodology Workshop, San Francisco. Immuno Diagnostics İnformation.

Priv. Doz. Dr. med. L. Weiss Chefarżt d. Klin.-Chem. Inst.

Städt. Krankenhaus München-Harlaching Sanatoriumsplatz 2

D-8000 München 90 